OPEN ACCESS

Edited by:

Ralf Jockers,

Université de Paris,

France

Reviewed by:

Josanne Vassallo,

University of Malta, Malta

Johan Verhaeghe,

KU Leuven Research \& Development,

Belgium

*Correspondence:

José Timsit

jose.timsit@gmail.com

Specialty section:

This article was submitted to

Cellular Endocrinology,

a section of the journal

Frontiers in Endocrinology

Received: 26 October 2021 Accepted: 13 December 2021

Published: 05 January 2022

Citation:

Timsit J, Ciangura $C$

Dubois-Laforgue D, Saint-Martin C and Bellanne-Chantelot C (2022) Pregnancy in Women With Monogenic

Diabetes due to Pathogenic Variants of the Glucokinase Gene: Lessons and Challenges.

Front. Endocrinol. 12:802423. doi: 10.3389/fendo.2021.802423

\section{Pregnancy in Women With Monogenic Diabetes due to Pathogenic Variants of the Glucokinase Gene: Lessons and Challenges}

\author{
José Timsit ${ }^{1,2,3^{*}}$, Cécile Cianguraa ${ }^{2,3,4}$, Danièle Dubois-Laforgue ${ }^{1,2,3,5}$, \\ Cécile Saint-Martin ${ }^{2,6}$ and Christine Bellanne-Chantelot ${ }^{2,3,6}$ \\ ${ }^{1}$ Department of Diabetology, Université de Paris, AP-HP, Cochin-Port-Royal Hospital, DMU ENDROMED, Paris, France, \\ ${ }^{2}$ PRISIS National Reference Center for Rare Diseases of Insulin Secretion and Insulin Sensitivity, Department of \\ Endocrinology, Diabetology and Reproductive Endocrinology, Assistance Publique-Hôpitaux de Paris, Saint-Antoine \\ University Hospital, Paris, France, ${ }^{3}$ Monogenic Diabetes Study Group of the Société Francophone du Diabète, Paris, France, \\ ${ }^{4}$ Department of Diabetology, Sorbonne Université, AP-HP, Pitié-Salpêtrière Hospital, Paris, France, 5 INSERM U1016, \\ Cochin Hospital, Paris, France, ${ }^{6}$ Department of Medical Genetics, Sorbonne Université, AP-HP, Pitié-Salpêtrière Hospital, \\ DMU BioGeM, Paris, France
}

Heterozygous loss-of-function variants of the glucokinase (GCK) gene are responsible for a subtype of maturity-onset diabetes of the young (MODY). GCK-MODY is characterized by a mild hyperglycemia, mainly due to a higher blood glucose threshold for insulin secretion, and an up-regulated glucose counterregulation. GCK-MODY patients are asymptomatic, are not exposed to diabetes long-term complications, and do not require treatment. The diagnosis of GCK-MODY is made on the discovery of hyperglycemia by systematic screening, or by family screening. The situation is peculiar in GCK-MODY women during pregnancy for three reasons: 1. the degree of maternal hyperglycemia is sufficient to induce pregnancy adverse outcomes, as in pregestational or gestational diabetes; 2 . the probability that a fetus inherits the maternal mutation is $50 \%$ and; 3. fetal insulin secretion is a major stimulus of fetal growth. Consequently, when the fetus has not inherited the maternal mutation, maternal hyperglycemia will trigger increased fetal insulin secretion and growth, with a high risk of macrosomia. By contrast, when the fetus has inherited the maternal mutation, its insulin secretion is set at the same threshold as the mother's, and no fetal growth excess will occur. Thus, treatment of maternal hyperglycemia is necessary only in the former situation, and will lead to a risk of fetal growth restriction in the latter. It has been recommended that the management of diabetes in GCK-MODY pregnant women should be guided by assessment of fetal growth by serial ultrasounds, and institution of insulin therapy when the abdominal circumference is $\geq 75$ th percentile, considered as a surrogate for the fetal genotype. This strategy has not been validated in women with in GCK-MODY. Recently, the feasibility of non-invasive fetal genotyping has been demonstrated, that will improve the care of these women. Several challenges persist, including the identification of women with GCK-MODY before or early in pregnancy, and the modalities of insulin therapy. 
Yet, retrospective observational studies have shown that fetal genotype, not maternal treatment with insulin, is the main determinant of fetal growth and of the risk of macrosomia. Thus, further studies are needed to specify the management of GCKMODY pregnant women during pregnancy.

Keywords: glucokinase, GCK-MODY, pregnancy, macrosomia, genotype, non-invasive fetal genotyping, insulin therapy

\section{INTRODUCTION}

Heterozygous pathogenic variants of the glucokinase $(G C K)$ gene are associated with an autosomal dominant monogenic diabetes called GCK-maturity-onset-diabetes of the young (GCKMODY). The GCK-MODY phenotype is restricted to a mild hyperglycemia that usually does not require any treatment. However, during pregnancy, the glucose levels of GCK-MODY mothers are high enough to potentially generate adverse outcomes similar to those observed in other forms of pregestational or gestational diabetes. The goal of the present review is to summarize current knowledge and challenges about this condition, its diagnosis, and its treatment during pregnancy. The literature was searched using the terms "glucokinase" or "GCK-MODY" or "MODY2" and "pregnancy", and all clinical publications were reviewed. Single case reports were not retained, unless they provided important information (e.g. the occurrence of congenital malformations).

\section{DIABETES IN PREGNANCY}

The relationships between diabetes and pregnancy are classically considered, according to the onset of diabetes before the beginning of pregnancy ("pregestational diabetes") or during the course of the pregnancy ("gestational diabetes") (1). Pregestational diabetes may be responsible for complications such as miscarriage, the occurrence of congenital malformations, and the subsequent increased risk of fetal or neonatal mortality. These complications are mainly related to the degree of hyperglycemia during the very first weeks of pregnancy (2). Pregestational as well as gestational diabetes may be responsible for many adverse issues for the mother, such as an increased frequency of hypertension, pre-eclampsia, pre-term delivery, and cesarean delivery; and for the baby, particularly macrosomia (i.e. excessive growth for gestational age), the associated risks of dystocia and neonatal hypoglycemia, and the consequences of prematurity (1). Moreover, maternal hyperglycemia might be responsible for the long-term occurrence of obesity and metabolic or cardiovascular diseases in the exposed offspring (3-6), although this remains a matter of debate (7).

The deleterious role of hyperglycemia during pregnancy has been further demonstrated by intervention studies in which "near normal" maternal blood glucose levels led to a decrease of adverse events $(8,9)$. These observations have led to a "glucocentric" approach of diabetes care in pregnancy, that is too restrictive (10), and other potentially modifiable risk factors have been identified, such as pre-pregnancy obesity, excessive weight gain during pregnancy, and gestational hypertension (1113). Recent studies also showed that in women with gestational diabetes, beyond the degree of hyperglycemia, the respective roles of insulin deficiency and insulin resistance in the pathophysiology of mother's diabetes may have differential impacts on pregnancy adverse events $(14,15)$. Moreover, in addition to maternal blood glucose levels, the fetal genotype may strongly influence birthweight and the risk of macrosomia (16).

\section{MONOGENIC DIABETES DUE TO GLUCOKINASE MOLECULAR ALTERATIONS}

Monogenic diabetes $(\mathrm{MgD})$ due to pathogenic alterations of the glucokinase gene $(G C K)$, the first identified genetic subtype of MODY (17), called GCK-MODY (formerly MODY2), is among the most common $\mathrm{MgD}$ subtype (18), with an estimated prevalence of $0.1 \%$ in the general population (19). Its unique characteristics have allowed drawing important lessons, particularly on the role of maternal and fetal genetics in the consequences of diabetes during pregnancy.

\section{The Genetics of GCK-MODY}

Heterozygous inactivating variants in GCK are responsible for GCK-MODY. More than 900 GCK mutations have been reported (Human Gene Mutation Database, HGMD-2021-3), including single-nucleotide variants (SNV) and rare exonic or gene deletions (20). The variants are distributed throughout the gene, with no mutational hotspots, and most are private. Pathogenic GCK variants lead to altered enzyme kinetics and more rarely to enzyme instability (20). No genotype/phenotype correlations have been reported $(18,21)$, with a similar phenotype in most patients, probably due to partial compensation of glucokinase activity by the wild-type allele (22). The molecular diagnosis of GCK-MODY in a proband relies on the search of SNV and large deletions, based on either analysis restricted to GCK (including sequencing and dosage analysis) if the proband's phenotype is highly suggestive of GCKMODY, or the sequencing of a multigene panel including GCK. In all cases, determining whether an identified variant is diseasecausing, a normal variation, or a variant of unknown significance is a key step in the diagnostic process reviewed in (23). 


\section{Pathophysiology of GCK-MODY}

Glucokinase catalyzes the phosphorylation of glucose to glucose6-phosphate, the first and rate-limiting step of glucose metabolism in the pancreatic beta-cell, which regulates insulin secretion in proportion to glucose metabolism within the physiological range. Glucokinase is thus considered as the "glucose sensor" of the pancreas (24). In patients with GCK-MODY, the curve of insulin secretion in response to increasing glucose concentrations is shifted to the right, and the glucose threshold for insulin release is higher than in normal individuals (25). Thus, fasting hyperglycemia is one main metabolic alteration in GCK-MODY. In the liver, glucokinase catalyzes the first step of glucose storage by glycogen synthesis, and patients with GCK-MODY harbor a decrease of hepatic glycogen synthesis and a relative increase of neoglucogenesis, which both participate to increased post-prandial glucose levels (26). GCK is also expressed in the pancreatic alpha-cells and in hypothalamus, and counterregulation to hypoglycemia also occurs at higher blood glucose levels in GCK-MODY patients $(27,28)$.

Insulin sensitivity is usually considered to be unaffected in GCK-MODY patients. However, studies showed that it was lower in patients with GCK mutations as compared to their nonaffected relatives, and was negatively associated with a mild deterioration of glucose tolerance, consistent with a deleterious effect of chronic hyperglycemia (29-31). Conversely, a longitudinal study suggested that the deterioration of glucose tolerance observed in some GCK-MODY patients was due to a decrease in insulin sensitivity, which could be related to aging, weight gain, and/or polygenic susceptibility (32). Whether this may also occur during pregnancy, a known situation of decreased insulin sensitivity, is not known. To our knowledge, no longitudinal study assessed whether glucose tolerance deteriorates in women with GCK-MODY during pregnancy, and improves after delivery. However, the fasting and 2 hours after a $75 \mathrm{~g}$ oral glucose tolerance test (OGTT) blood glucose values measured in 44 pregnant women with GCK-MODY were in the same range as those of non-pregnant GCK-MODY patients (19).

\section{The Main Characteristics of GCK-MODY Patients}

As compared to Type 1, Type 2 and other monogenic diabetes, GCK-MODY has unique characteristics reviewed in (18). The main feature observed in GCK-MODY patients is a mild fasting hyperglycemia, typically in a narrow range $(5.4-8.3 \mathrm{mmol} / \mathrm{L})$, with an increase 2 hours after a $75 \mathrm{~g}$ OGTT usually $<3.0 \mathrm{mmol} / \mathrm{L}$ $(21,33,34) . \mathrm{HbA}_{1 \mathrm{c}}$ values are comprised between 38 and 60 $\mathrm{mmol} / \mathrm{mol}(5.6-7.6 \%)$, and allow good discrimination of the patients from non-carriers relatives, and from patients with Type 1 or Type 2 diabetes (35). Hyperglycemia is present from birth and blood glucose levels increase mildly with age, as observed in non-diabetic individuals, albeit at a higher level $(33,35,36)$. The penetrance of this phenotype is complete, all carriers of a GCK defect being hyperglycemic, generally at the same level (33).

Patients with GCK-MODY are clinically asymptomatic and, in the absence of other risk factors, micro- and macrovascular complications are rare, except for a mild non-clinically significant retinopathy, even in patients with long-standing hyperglycemia (36).

Consequently, outside pregnancy, no treatment of hyperglycemia is warranted in GCK-MODY patients. Moreover, treatments of hyperglycemia are not effective in these patients. In prospective studies, $20-50 \%$ of GCK-MODY patients were treated with oral hypoglycemic agents or insulin before the diagnosis was made. $\mathrm{HbA}_{1 \mathrm{c}}$ values were very similar in treated and untreated patients, and were not affected by treatment withdrawal (37-39). It is likely that the up-regulated counterregulation of GCK-MODY patients will prevent strict normalization of blood glucose values $(27,28)$.

\section{RISKS ASSOCIATED WITH PREGNANCY IN WOMEN WITH GCK-MODY}

\section{The Rate of Miscarriage Would Be Expected to Be Increased Given the Blood Glucose and $\mathrm{HbA}_{1 \mathrm{c}}$ Levels Observed in GCK-MODY Women}

It has been reported to be increased compared to that of the general population (33\% of 56 pregnancies) in one study (40), but similar to the general population rate in a further study by the same group on a larger population (17\% of 119 pregnancies) (41), and in an additional independent study (19\% of 128 pregnancies) (42).

\section{The Risk for Congenital Malformations Has Not Been Systematically Assessed}

Blood glucose levels of GCK-MODY patients are compatible with a slightly increased risk, i.e. a $30 \%$ risk increase per $1 \%(11 \mathrm{mmol} / \mathrm{mol})$ increase in $\mathrm{HbA}_{1 \mathrm{c}}$ above $6.3 \%(45 \mathrm{mmol} / \mathrm{mol})$, if one refers to data obtained in women with pregestational diabetes (2). One case of caudal regression syndrome was reported, and the potential benefit of systematic peri-conceptual folic acid supplementation in women with known GCK-MODY has been suggested (as actually recommended in the general population) (43). A pulmonary valve stenosis was reported in a child born to a GCK-MODY mother, whose early pregnancy $\mathrm{HbA}_{1 \mathrm{c}}$ was $6.5 \%(48 \mathrm{mmol} / \mathrm{mol})$ (44). Also, 4 congenital malformations were reported among 99 offspring born to mothers with GCK-MODY, which could be higher than in the general population, but no further information was available (41). Thus, in GCK-MODY women with a pre-conceptual $\mathrm{HbA}_{1 \mathrm{c}}>6.3 \%(45 \mathrm{mmol} / \mathrm{mol})$, insulin therapy could be recommended to prevent the risk of congenital malformations.

\section{Unaffected Offspring of Mothers With GCK-MODY Are at High Risk of Macrosomia}

Blood glucose and $\mathrm{HbA}_{1 \mathrm{c}}$ values observed in patients with GCKMODY confer a high risk of macrosomia (45). In women with pregestational diabetes, the probability of large for gestational age (LGA, defined by a birthweight $>90^{\text {th }}$ percentile) offspring increases linearly with third trimester $\mathrm{HbA}_{1 \mathrm{c}}$ values above 36.6 $\mathrm{mol} / \mathrm{mol}(5.5 \%)$ and is almost maximal (65\% risk) for a $53 \mathrm{mmol} / \mathrm{mol}$ 
(7.0\%) value (12). Even in offspring born to women with mild gestational diabetes, the risk of LGA increased linearly with increasing blood glucose levels up to $5.8 \mathrm{mmol} / \mathrm{L}$ fasting and to $11.1 \mathrm{mmol} / \mathrm{L}$ at 2 hours of a $75 \mathrm{~g}$ OGTT, and was associated with a parallel increase in cord blood C-peptide levels (a measure of insulin secretion by the fetus) (46).

Given the autosomal transmission of GCK-MODY, at each pregnancy the probability that a fetus will inherit the maternal GCK mutation is $50 \%$. In this context, fetal growth will dependent both on the degree of maternal hyperglycemia, and on the ability of the fetus to increase insulin secretion in response to hyperglycemia, i.e., its GCK genotype. Indeed, the seminal report by A.T. Hattersley et al. on GCK-MODY families clearly showed that non-affected offspring born to affected mothers had a $600 \mathrm{~g}$ higher birth weight than affected offspring born to affected mothers and than non-affected offspring born to nonaffected mothers (47). According to the Pedersen hypothesis (48), this suggested that accelerated fetal growth was induced by increased fetal insulin secretion by non-affected fetuses in response to maternal hyperglycemia, and that fetal growth was normal in affected fetuses since their insulin secretion was set at the same level as their mother's. Observational studies have consistently confirmed this report $(41,42,49-52)$, and showed that the frequency of macrosomia (birthweight $>4000 \mathrm{~g}$ ) and/or of LGA offspring were high $(33-65 \%)$ in the first situation, as compared to the latter (4-13\%, i.e. the expected rate of LGA in the general population) (Table 1). However, in one series 5/15 affected offspring born to affected mothers were macrosomic. These five infants were born to 4 mothers who had had 10 other pregnancies, and delivered 8 macrosomic infants. This suggested that confounding factors, yet unidentified, may have played a role in the occurrence of excessive fetal growth (42). Of note, in the offspring of an unaffected mother inheriting a GCK mutation from their father, birth weight was reduced by $500 \mathrm{~g}$, compared to controls, confirming the central role of fetal insulin secretion in the fetal growth (47).

Macrosomia can be associated with increased frequencies of many perinatal adverse outcomes, including shoulder dystocia, fetal distress, perineal tears, induced preterm delivery and Cesarean delivery (CS), neonatal hypoglycemia, and neonatal respiratory distress. These complications have been reported in the context of pregestational diabetes, as well as in mild gestational diabetes, where blood glucose levels are quite similar to that observed in GCK-MODY (46). Shoulder dystocia was reported in 4/15 macrosomic non-affected babies born to GCK-MODY mothers (50). Other adverse outcomes, mainly emergency or planned CS due to macrosomia, have also been reported (42). However, the rates of these complications have not been systematically assessed in unaffected offspring born to affected mothers, compared to affected offspring.

\section{Unaffected Offspring of Mothers With GCK-MODY Do Not Exhibit Clinical or Metabolic Abnormalities in the Long Term}

In various situations, fetal exposure to maternal diabetes has been associated with long-term deleterious effects, particularly defects in glucose-stimulated insulin secretion and hyperglycemia. This has been shown in offspring of mothers with type 2 diabetes (53-55), with monogenic diabetes associated with hepatocyte nuclear factor 1 alpha (56), but also with type 1 diabetes (57). As regards GCKMODY, two studies demonstrated no obvious long-term effects in offspring of GCK-MODY mothers. In the first one, 42 adult nonmutation carriers born to GCK-MODY mothers were compared to 39 non-mutation carriers born to unaffected mothers, at a median age of 42 and 36 years, respectively. No differences were observed in fasting and post-load (75 g OGTT) glucose values, insulin secretion and insulin sensitivity indexes, body mass index (BMI), blood pressure and lipid profiles (49). In the second study,

TABLE 1 | Birthweight percentiles, frequency of large for gestational age newborns and gestational age at delivery according to fetal genotype and treatment of diabetes in GCK-MODY mothers.

\begin{tabular}{|c|c|c|c|c|c|c|}
\hline \multirow[t]{2}{*}{ Reference $\mathbf{N}^{\circ}$} & \multicolumn{2}{|c|}{ Effect of fetal genotype } & \multicolumn{4}{|c|}{ Effect of fetal genotype and maternal treatment } \\
\hline & GCK - & GCK + & GCK - diet & GCK - insulin & GCK + diet & GCK + insulin \\
\hline \multirow[t]{3}{*}{$(50)$} & $P c=85 \pm 21$ & $P C=47 \pm 31(44)^{\star}$ & $\mathrm{Pc}=86 \pm 22(19)$ & $\mathrm{PC}=84 \pm 21(19)$ & $\mathrm{Pc}=51 \pm 30(30)$ & $P C=39 \pm 33(14)$ \\
\hline & LGA = 21/38 (55\%) & LGA $=4 / 44(9 \%)^{*}$ & - & - & - & - \\
\hline & $T=38.1 \pm 1.7$ & $\mathrm{~T}=38.7 \pm 2.6^{\dagger}$ & $\mathrm{T}=38.9 \pm 1.7$ & $\mathrm{~T}=37.3 \pm 1.1^{\ddagger}$ & $\mathrm{T}=39.1 \pm 2.7$ & $\mathrm{~T}=37.8 \pm 2.0^{\ddagger}$ \\
\hline \multirow[t]{3}{*}{$(51)$} & - & - & - & - & - & - \\
\hline & LGA = 9/22 (41\%) & LGA $=4 / 45(9 \%)^{*}$ & - & - & - & - \\
\hline & $T=38.7 \pm 2.7$ & $T=39.3 \pm 2.3$ & - & - & - & - \\
\hline \multirow[t]{3}{*}{$(52)$} & $\mathrm{PC}=75 \pm 27(12)$ & $\mathrm{PC}=41 \pm 31(28)^{\star}$ & $\mathrm{PC}=86 \pm 10(8)$ & $P_{C}=53 \pm 37(4)^{\ddagger}$ & $\mathrm{Pc}=41 \pm 31(19)$ & $P_{C}=40 \pm 31(9)$ \\
\hline & LGA = 4/12 (33\%) & LGA $=1 / 28(4 \%)^{*}$ & - & - & - & - \\
\hline & $T=39.3 \pm 1.0$ & $T=38.4 \pm 2.3$ & $\mathrm{~T}=39.3$ & $\mathrm{~T}=39.4$ & $\mathrm{~T}=38.8$ & T 37.6 \\
\hline \multirow[t]{3}{*}{$(42)$} & - & - & $P C=90 \pm 8(3)$ & $\mathrm{PC}=84 \pm 22(9)$ & $\mathrm{PC}=58 \pm 33(15)$ & $P_{C}=34 \pm 27(8)$ \\
\hline & - & - & - & - & - & - \\
\hline & - & - & $\mathrm{T}=36$ & $\mathrm{~T}=37$ & $\mathrm{~T}=40.4$ & $\mathrm{~T}=38.0^{\ddagger}$ \\
\hline \multirow[t]{3}{*}{$(41)$} & - & - & $P C=69 \pm 34(12)$ & $P c=92 \pm 18(11)$ & $\mathrm{Pc}=50 \pm 28(28)$ & $P C=64 \pm 35(11)$ \\
\hline & LGA = 15/23 (65\%) & LGA $=5 / 39(13 \%)^{*}$ & LGA = 6/12 (50\%) & LGA = 9/11 (82\%) & $L G A=1 / 28(4 \%)$ & $L G A=4 / 11(36 \%)$ \\
\hline & - & - & $T=39.5 \pm 1.5$ & $\mathrm{~T}=38.3 \pm 1.0^{\ddagger}$ & $\mathrm{T}=39.6 \pm 1.0$ & $\mathrm{~T}=38.7 \pm 1.4^{\ddagger}$ \\
\hline
\end{tabular}

Data are: $1^{\text {st }}$ line: mean $\pm S D$ of birth weight percentiles $(P C)$ with numbers of cases into parentheses; $2^{\text {nd }}$ line: numbers of large for gestational age ( $\left.L G A\right)$ newborns/total numbers of newborns, with percentages into parentheses; and $3^{\text {rd }}$ line: mean term (T) at delivery (weeks). LGA was defined as a corrected birthweight $>90^{\text {th }}$ percentile. * significantly lower than in GCK - babies; ${ }^{\dagger}$ significantly higher than in GCK - babies; ${ }^{*}$ significantly lower than in diet treated babies. 
15 unaffected offspring of GCK-MODY mothers were compared to 14 unaffected offspring of GCK-MODY fathers. Although the former were on average $720 \mathrm{~g}$ heavier at birth, they did not display any alteration of glucose tolerance, insulin secretion, BMI, percentage of body fat mass, and blood pressure, at 36-39 years of age (58). These observations suggest that fetal exposure to maternal hyperglycemia ("metabolic imprinting") is not always sufficient to induce long-term metabolic abnormalities in the offspring.

\section{THE DIAGNOSIS OF GCK-MODY BEFORE AND DURING THE COURSE OF PREGNANCY}

\section{Outside the Pregnancy, the Diagnosis of GCK-MODY May Be Raised on the Discovery of Hyperglycemia}

In young and lean individuals, type 1 diabetes should be excluded by the absence of diabetes-related autoantibodies (59). The criteria in favor of GCK-MODY include the mild degree of hyperglycemia (5.5-8.0 mmol/L), a $2 \mathrm{hr}$ increment $<4.6 \mathrm{mmol} / \mathrm{L}$ on a $75 \mathrm{~g}$ OGTT, and a family history of hyperglycemia, including gestational diabetes, suggesting an autosomal dominant inheritance (34). A young age and a normal BMI at the time of first recognition of hyperglycemia are also in favor of the diagnosis, since they are not typical of Type 2 diabetes. The family history of hyperglycemia may be unrecognized, or even absent in the rare cases of de novo occurrence of a GCK mutation. In all cases, the suspicion of GCK-MODY in a proband should lead to measure fasting blood glucose in the parents (34). It is also important to systematically screen fasting blood glucose in relatives of a patient with GCK-MODY, since this will identify women of child-bearing age who should be genetically tested. Nevertheless, it has been estimated that almost all GCK-MODY cases are not diagnosed (19). Thus, it can be anticipated that in the majority of women with GCK-MODY hyperglycemia will be first detected during pregnancy, owing to screening for gestational diabetes.

\section{Screening for Gestational Diabetes Is an Opportunity to Diagnose GCK-MODY}

For decades, the diagnosis of gestational diabetes has been a matter of debate as regards the women who should be screened, the optimal term of pregnancy to perform screening, and which test should be used (60). Some have suggested to screen all women when planning pregnancy, or at the latest at first prenatal contact, by measuring fasting plasma glucose $(61,62)$, which could be a good opportunity for GCK-MODY diagnosis. However, it is generally recommended to screen women with risk factors (age $\geq 35$ years, pre-pregnancy BMI $\geq 25 \mathrm{~kg} / \mathrm{m}^{2}$, firstdegree relative with diabetes, history of gestational diabetes, or of delivery of a macrosomic neonate), as soon as possible during pregnancy, and all women at 24 weeks of gestation (60). Among the risk factors for gestational diabetes, some may be present in women with GCK-MODY.
The reported prevalence of GCK-MODY among women with a diagnosis of gestational diabetes is typically $0.5-2 \%$, but varies considerably (from 0 to $80 \%$ ) according to the criteria used for genetic screening reviewed in $(63,64)$. Using stringent criteria to select women for genetic screening will increase the diagnosis rate, but at the cost of a lower sensitivity. New pregnancy-specific screening criteria (NSC) have been defined in a population-based study of women with gestational diabetes, of whom $\sim 1 \%$ had a confirmed GCK-MODY (19). They include an antepartum fasting blood glucose $\geq 5.5 \mathrm{mmol} / \mathrm{L}(99 \mathrm{mg} / \mathrm{dl})$ and a prepregnancy BMI $<25 \mathrm{~kg} / \mathrm{m}^{2}$. In the studied white European population, these criteria had a $68 \%$ sensitivity and a $99 \%$ specificity for the diagnosis of GCK-MODY. Using these criteria, the number of women needed to test to find one GCK-MODY case was 2.7. Decreasing or increasing the BMI threshold decreased or increased sensitivity, respectively, with no major effect on specificity (19). A multiethnic Australian study confirmed that these criteria performed well in women of AngloCeltic origin, but not in those of Asian or Indian origin (65). Among Danish women with diet-treated gestational diabetes, 2\% had GCK-MODY, but a BMI $<25 \mathrm{~kg} / \mathrm{m}^{2}$ was not discriminant in this study (66). Thus, more multiethnic studies in women with gestational diabetes are needed to refine the criteria for genetic screening, and the diagnosis of GCK-MODY in early pregnancy is currently an unsolved challenge.

\section{MANAGEMENT OF PREGNANCY IN WOMEN WITH GCK-MODY}

\section{Current Recommendations on the Treatment of GCK-MODY During Pregnancy}

These recommendations mainly apply to the use of insulin therapy to prevent macrosomia and its potential consequences reviewed in (67). As mentioned, when the fetus has not inherited the maternal mutation, the risk of macrosomia is high, and normalization of maternal blood glucose levels is necessary. By contrast, when the fetus has inherited the maternal mutation, treatment of maternal hyperglycemia should be avoided because of the risk of fetal growth restriction due to a decrease of fetal blood glucose values under the insulin secretion threshold (68, 69). Thus, knowing the fetal genotype will determine whether the maternal hyperglycemia should be treated. The proof of concept of this approach was obtained in two GCK-MODY women in whom chorionic villous sampling, performed for other reasons, showed the presence of the mutation in the fetuses. No treatment of diabetes was initiated and the women delivered normal-weight babies $(70,71)$.

However, invasive prenatal diagnosis conveys risks and is not appropriate for a benign condition, and the fetal genotype is unknown in almost all cases. Thus, so far it has been suggested that the course of fetal growth, monitored by serial ultrasounds (US), may be used as a surrogate for the fetal genotype, and for the need for treatment of maternal hyperglycemia (18).

This strategy is adapted from studies performed in women with "common" gestational diabetes. All offspring of women 
with gestational diabetes are not at risk for macrosomia, and "too tight" control of maternal hyperglycemia may lead to an increased risk of intrauterine growth retardation (72). Thus, several randomized trials were performed in women with gestational diabetes, comparing the initiation of insulin therapy based on maternal blood glucose values, or on an accelerated fetal growth, defined by an abdominal circumference (AC) $\geq$ $70^{\text {th }}-75^{\text {th }}$ percentile on US (73-76). US allowed to identify the infants at low risk of macrosomia, and to avoid insulin therapy in their mothers, with no increase of pregnancy adverse outcomes, particularly no increase of LGA, nor of small for gestational age offspring (77). Of note, insulin therapy was also introduced in the US groups when maternal blood glucose values exceeded safety levels, $6.7 \mathrm{mmol} / \mathrm{L}$ (120 mg/dl) fasting or $11.1 \mathrm{mmol} / \mathrm{L}(200 \mathrm{mg} / \mathrm{dl})$ post-meal, i.e., much above the usually recommended targets in women with gestational diabetes. However, when insulin therapy had to be initiated in at risk pregnancies, strict blood glucose targets $(4.4$ and $6.1 \mathrm{mmol} / \mathrm{L}, 80$ and $110 \mathrm{mg} / \mathrm{dl}$, fasting and after meals, respectively) were set to reduce the risk of macrosomia (77). Although this approach has been validated in a real life setting (78), its benefits have been questioned in a recent review (79) and it is not part of the current guidelines on the management of gestational diabetes (1).

The same approach has been recommended in pregnant women with GCK-MODY (68), including an US every two weeks, starting from 26 weeks of gestation, with the $\mathrm{AC} \geq 75^{\text {th }}$ pc threshold for initiation of insulin therapy (Figure 1). In women treated with insulin, it is recommended that delivery should be induced at 38 weeks (18). Several potential pitfalls can be raised, including the limited accuracy of fetal US to predict the risk of macrosomia, due to intra-and inter-observer variability of AC measurement, the restricted availability of high-quality US, and the relatively late identification of the risk of macrosomia, at a time when intervention might be less efficient (80). To date, this strategy has not been validated in GCK-MODY and should be considered as expert opinion.

A prospective study has been recently completed in women with GCK-MODY, comparing the two strategies, i.e., institution of insulin therapy according to blood glucose values or to fetal growth (ClinicalTrials-NCT02556840). Analysis is ongoing and will hopefully show whether the second approach is safe, and to what extent insulin therapy is efficient to control maternal blood glucose levels and fetal growth in unaffected offspring.

\section{Non-Invasive Prenatal Testing}

The presence of fetal DNA in maternal plasma from the early first trimester of gestation has allowed the development of noninvasive prenatal testing (NIPT) for single-gene diseases (81). However, NIPT for maternally inherited variants presents technological and analytical challenges because only a small proportion (5\% to $20 \%$ ) of the total cell-free DNA in maternal plasma is derived from the fetus during early pregnancy. Two major methods for NIPT have been developed. One uses droplet digital PCR to quantify reference and alternate alleles and to estimate the allelic balance of the mutation itself. The second consists in the identification of at-risk maternal haplotype at a specific locus using high-throughput DNA sequencing technologies and the determination of the maternal haplotype

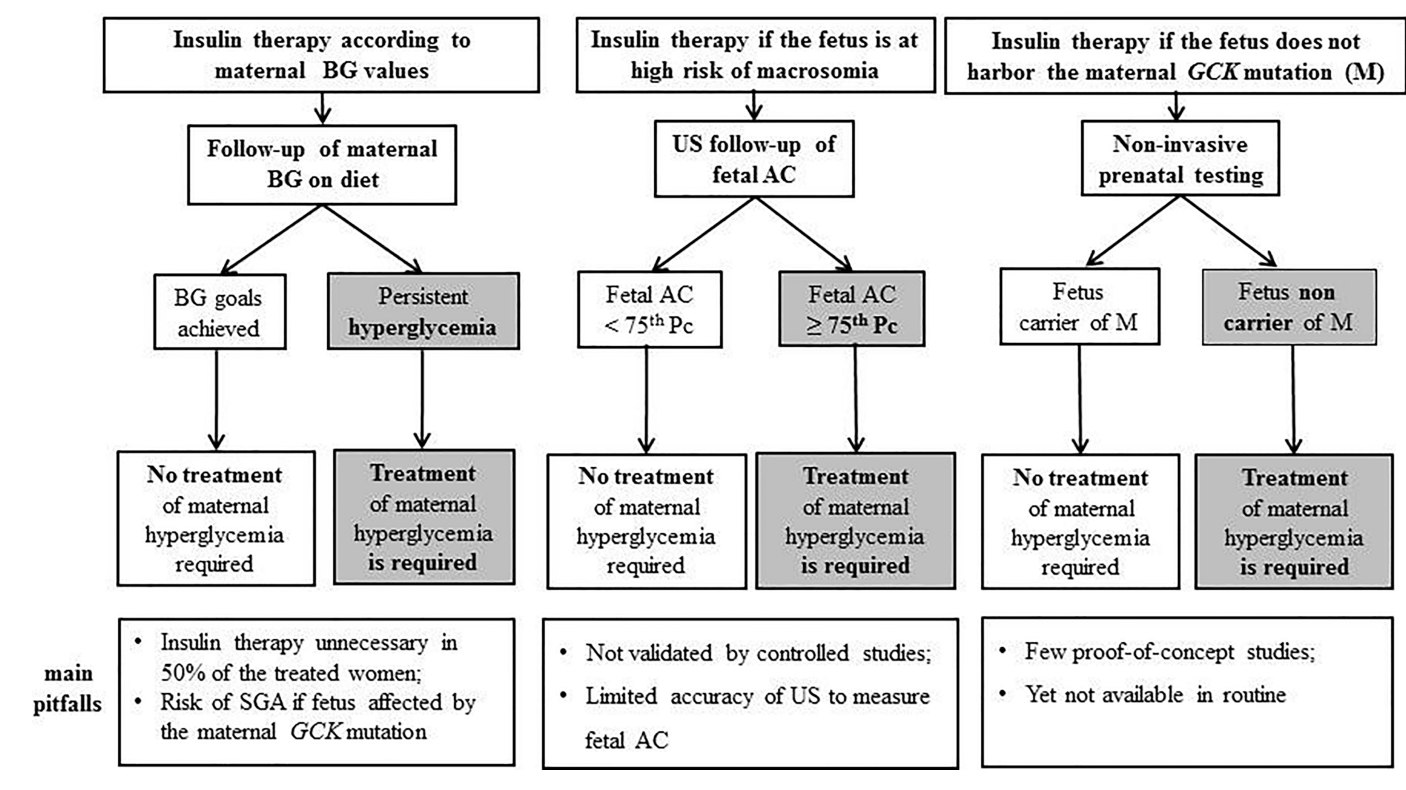

FIGURE 1 | Suggested algorithms to initiate insulin therapy in pregnant women with GCK-MODY. The left part of the figure describes the approach based, as in "common" gestational diabetes, on maternal blood glucose (BG) values. The middle part illustrates current recommendations, based on the serial measurement of fetal abdominal circumference (AC) by ultrasounds (US), and initiation of insulin therapy when $A C$ is $\geq 75^{\text {th }}$ percentile (PC), which suggests the absence of the maternal GCK mutation in the fetus and a risk of macrosomia. In the right part, initiation of insulin therapy will be based on the absence of the maternal mutation (M) in the fetus, diagnosed by non-invasive prenatal testing. The bottom part of the figure indicates the main pitfalls of each strategy. SGA, small for gestational age. 
transmitted to the fetus, based on relative haplotype dosage estimation. Both methods have recently been successfully performed in pregnant women with GCK-MODY as proof-ofconcept studies (82-84). In these studies, NIPT could effectively be performed from 12 weeks of gestation, with a current 3-5 week time to results, and both high sensitivity (87\%) and specificity (100\%) (82). The possibility of an early diagnosis could also improve the efficiency of treatment of maternal hyperglycemia to prevent macrosomia (80). Yet, NIPT is not routinely available for GCK-MODY but these preliminary results are promising, particularly those based on relative haplotype dosage estimation. This latter approach will benefit from the development of novel high-throughput sequencing technologies based on long read sequencing, facilitating the reconstruction of haplotypes.

\section{Is Insulin Therapy Effective in Women With GCK-MODY?}

Although it is currently recommended to institute insulin therapy in GCK-MODY women whose babies are at high risk of macrosomia, this strategy has not been implemented in routine practice (41). Thus, in the majority of reported cases, insulin therapy was instituted on the basis of maternal capillary blood glucose upon diet, as recommended in "common" gestational diabetes, or on the discovery of macrosomia by routine US (41) (Figure 1). Moreover, no prospective study as defined the best modalities of the treatment and, outside pregnancy, no effect of insulin therapy on $\mathrm{HbA}_{1 \mathrm{c}}$ levels was observed (37-39).

In pregnant women with GCK-MODY, scarce reports suggested that insulin therapy may be effective. During two consecutive pregnancies, one woman was treated with insulin, $1 \mathrm{U} / \mathrm{kg} / \mathrm{d}$ from 10-12 gestation weeks, with normalization of fructosamine values. She delivered a small-for-gestational age $\left(1^{\text {st }}\right.$ percentile) unaffected baby, and a normal weight $\left(30^{\text {th }}\right.$ percentile) affected baby (68). In another report, one woman treated with $1.43 \mathrm{U} / \mathrm{kg} / \mathrm{d}$ at 30-38 gestation weeks delivered a normal weight $\left(25^{\text {th }}\right.$ percentile) unaffected baby (83). Also, a Japanese study reported that the mean birth weight was lower in unaffected babies born to insulin-treated vs. diet treated mothers [(52), Table 1].

However, several retrospective studies have assessed the respective effects of fetal genotype and of treatment with diet or insulin on pregnancy outcomes, and showed that the main determinant of offspring birth weight and of the risk of macrosomia was the fetal genotype, not the treatment of the mother (Table 1). Specifically, birth weights were higher in nonaffected vs. affected babies, irrespective of the treatment (insulin vs. diet) (41, 42, 50-52). In all studies but one, treatment with insulin did not significantly lower birth weight of affected or unaffected offspring (Table 1). In one study, LGA (51 vs. 26\%) and neonatal hypoglycemia ( 24 vs. $3 \%$ ) were even more frequent in offspring of insulin-treated vs. diet-treated mothers (41). Insulin therapy was also associated with undesirable side effects. The occurrence of maternal hypoglycemia in $56 \%$ of the women, including severe hypoglycemia in $23 \%$, was reported in one series (42). Moreover, in almost all studies, insulin therapy was associated with lower gestational age at birth, and with a higher incidence of labor induction and Cesarean deliveries, likely reflecting obstetricians' concerns when pregnant women are treated with insulin (50).

Several hypotheses have been made to explain the poor results of insulin therapy in this context. All these studies were retrospective and some spanned over several decades. Selection bias likely occurred, leading to treat more frequently women with a more pronounced hyperglycemia and/or with already large babies, as suggested by the higher rate of macrosomia in offspring born to insulin-treated mothers in one study (41). Also, insulin dosage was highly variable, ranging 0.1-1.5 U/kg/d, and often may have been insufficient to lower blood glucose levels to the strict targets required to prevent accelerated fetal growth (85). Indeed, one series reported fasting and post-meal blood glucose profiles, recorded in 16 insulin-treated mothers with GCKMODY during the first and the third trimester of pregnancy, that demonstrated glucose values well above recommended targets in almost all women (41). Gestational age at initiation of insulin therapy was also highly variable (from pre-conceptual to 38 weeks of gestation), while it has been suggested that early normalization of maternal blood glucose is necessary to prevent macrosomia reviewed in (80). Lastly, one further barrier could be the up-regulated counterregulation in GCK-MODY that will prevent strict normalization of blood glucose values. It has been suggested that high insulin doses, e.g. $\geq 1 \mathrm{U} / \mathrm{kg} / \mathrm{d}$., may be needed to normalize blood glucose, but this may be at the cost of a high risk of hypoglycemia. These difficulties are well recognized and account for the recommendation to induce delivery at 38 weeks of gestation in GCK-MODY women treated with insulin $(18,50)$.

\section{IN SEVERAL AREAS THERE COULD BE OPPORTUNITIES TO IMPROVE THE MANAGEMENT AND THE PROGNOSIS OF PREGNANCY IN WOMEN WITH GCK-MODY}

\section{Improving the Diagnosis of GCK-MODY in the Women Before and During Pregnancy}

Since patients are asymptomatic the diagnosis of GCK-MODY relies on systematic screening. Information about monogenic diabetes should be delivered to healthcare workers and in the general population. The fortuitous discovery of a mild hyperglycemia should not be neglected. First-degree relatives of probands with GCK-MODY should systematically be screened.

During pregnancy, early diagnosis of GCK-MODY is difficult since currently only women with risk factors for gestational diabetes are screened in the first trimester. Also, the performance of algorithms to select hyperglycemic women to be genetically screened should be evaluated prospectively in multiethnic studies.

\section{Improving the Diagnosis in the Fetus}

In pregnant women with a confirmed GCK-MODY, noninvasive fetal genotyping will hopefully replace the US-guided management when routinely available. This will considerably 
lighten the care and the follow-up of pregnancy in women whose fetuses have inherited the mutation (Figure 1).

\section{The Best Modalities and the Efficiency of Insulin Therapy Remain to be Determined}

As fetal growth is highly sensitive to mild degrees of hyperglycemia, treatment of maternal hyperglycemia, at the earliest during pregnancy and with strict glycemic targets, is mandatory to decrease adverse events (86). However, decreasing blood glucose values with insulin is associated with a high risk of maternal hypoglycemia, including severe episodes (87). Continuous glucose monitoring during pregnancy improves maternal glycemia and pregnancy outcomes, and is now recommended in pregnant women with type 1 diabetes (88). Moreover, it has been suggested that closed-loop and sensoraugmented pump insulin delivery could be efficient to lower blood glucose levels without increasing the risk of severe hypoglycemia in pregnant women (89). Whether this could be used to overcome the up-regulated counterregulation without increasing the risk of hypoglycemia in women with GCK-MODY is not known. Since it is difficult to perform studies in pregnant women, one may suggest to first test the feasibility of this approach in patients with GCK-MODY outside pregnancy.

Yet, it is unlikely that other treatments could be used. Sulfonylureas are not a good choice, since they cross the placental barrier, stimulate fetal insulin secretion and are responsible for macrosomia and neonatal hypoglycemia (90). Theoretically, metformin, alone or in association with insulin, could be used. However, metformin crosses the placental barrier, and concerns have been raised about undesirable long-term

\section{REFERENCES}

1. American Diabetes Association. Management of Diabetes in Pregnancy: Standards of Medical Care in Diabetes-2021. Diabetes Care (2021) 44 (Supplement 1):S200-10. doi: 10.2337/dc21-S014

2. Bell R, Glinianaia SV, Tennant PW, Bilous RW, Rankin J. Peri-Conception Hyperglycaemia and Nephropathy Are Associated With Risk of Congenital Anomaly in Women With Pre-Existing Diabetes: A Population-Based Cohort Study. Diabetologia (2012) 55:936-47. doi: 10.1007/s00125-012-2455-y

3. Harder T, Rodekamp E, Schellong K, Dudenhausen JW, Plagemann A. Birth Weight and Subsequent Risk of Type 2 Diabetes: A Meta-Analysis. Am J Epidemiol (2007) 165:849-57. doi: 10.1093/aje/kwk071

4. Dabelea D, Mayer-Davis EJ, Lamichhane AP, D'Agostino RBJr, Liese AD, Vehik KS, et al. Association of Intrauterine Exposure to Maternal Diabetes and Obesity With Type 2 Diabetes in Youth: The SEARCH Case-Control Study. Diabetes Care (2008) 31:1422-6. doi: 10.2337/dc07-2417

5. Damm P, Houshmand-Oeregaard A, Kelstrup L, Lauenborg J, Mathiesen ER, Clausen TD. Gestational Diabetes Mellitus and Long-Term Consequences for Mother and Offspring: A View From Denmark. Diabetologia (2016) 59:13969. doi: 10.1007/s00125-016-3985-5

6. Bianco ME, Josefson JL. Hyperglycemia During Pregnancy and Long-Term Offspring Outcomes. Curr Diabetes Rep (2019) 19:143. doi: 10.1007/s11892019-1267-6

7. Donovan LE, Cundy T. Does Exposure to Hyperglycaemia In Utero Increase the Risk of Obesity and Diabetes in the Offspring? A Critical Reappraisal. Diabetes Med (2015) 32:295-304. doi: 10.1111/dme.12625

8. McIntyre HD, Catalano P, Zhang C, Desoye G, Mathiesen ER, Damm P. Gestational Diabetes Mellitus. Nat Rev Dis Primers (2019) 5:47. doi: 10.1038/ s41572-019-0098-8 effects in exposed children (91). Moreover, its potential benefit has not been assessed in patients with GCK-MODY outside pregnancy.

\section{CONCLUSION}

GCK-MODY is a quasi-experimental human model that allowed to define the respective roles of maternal hyperglycemia and fetal genotype on fetal growth, and to confirm the central role of fetal insulin secretion in fetal growth. It is also a unique situation suggesting that fetal exposure to maternal hyperglycemia is not always responsible per se for late adverse consequences in the offspring. Non-invasive fetal genotyping is a major advance in the care of GCK-MODY women, since it will allow determining those women whose diabetes should be treated during pregnancy. Challenges persist in the accurate identification of women with GCK-MODY before or in early pregnancy, and in the definition of therapeutic modalities during pregnancy. Multicenter studies or registers could be useful to improve our knowledge in these fields.

\section{AUTHOR CONTRIBUTIONS}

JT, CS-M, and CB-C wrote the draft of the manuscript. All authors contributed to the writing and the reviewing of the manuscript. All authors approved the final version of the manuscript.

9. Ringholm L, Damm P, Mathiesen ER. Improving Pregnancy Outcomes in Women With Diabetes Mellitus: Modern Management. Nat Rev Endocrinol (2019) 15:406-16. doi: 10.1038/s41574-019-0197-3

10. Cooray SD, Boyle JA, Soldatos G, Thangaratinam S, Teede HJ. The Need for Personalized Risk-Stratified Approaches to Treatment for Gestational Diabetes: A Narrative Review. Semin Reprod Med (2020) 38:384-8. doi: 10.1055/s-0041-1723778

11. Catalano PM, McIntyre HD, Cruickshank JK, McCance DR, Dyer AR, Metzger BE, et al. The Hyperglycemia and Adverse Pregnancy Outcome Study: Associations of GDM and Obesity With Pregnancy Outcomes. Diabetes Care (2012) 35:780-6. doi: 10.2337/dc11-1790

12. Glinianaia SV, Tennant PW, Bilous RW, Rankin J, Bell R. HbAlc and Birthweight in Women With Pre-Conception Type 1 and Type 2 Diabetes: A Population-Based Cohort Study. Diabetologia (2012) 55:3193-203. doi: 10.1007/s00125-012-2721-z

13. Shi P, Liu A, Yin X. Association Between Gestational Weight Gain in Women With Gestational Diabetes Mellitus and Adverse Pregnancy Outcomes: A Retrospective Cohort Study. BMC Pregnancy Childbirth (2021) 21:508. doi: 10.1186/s12884-021-03982-4

14. Benhalima K, Van Crombrugge P, Moyson C, Verhaeghe J, Vandeginste S, Verlaenen $\mathrm{H}$, et al. Characteristics and Pregnancy Outcomes Across Gestational Diabetes Mellitus Subtypes Based on Insulin Resistance. Diabetologia (2019) 62:2118-28. doi: 10.1007/s00125-019-4961-7

15. Madsen LR, Gibbons KS, Ma RCW, Tam WH, Catalano PM, Sacks DA, et al. Do Variations in Insulin Sensitivity and Insulin Secretion in Pregnancy Predict Differences in Obstetric and Neonatal Outcomes? Diabetologia (2021) 64:304-12. doi: 10.1007/s00125-020-05323-0

16. Hughes AE, Nodzenski M, Beaumont RN, Talbot O, Shields BM, Scholtens DM, et al. Fetal Genotype and Maternal Glucose Have Independent and 
Additive Effects on Birth Weight. Diabetes (2018) 67:1024-9. doi: 10.2337/ db17-1188

17. Froguel P, Vaxillaire M, Sun F, Velho G, Zouali H, Butel MO, et al. Close Linkage of Glucokinase Locus on Chromosome $7 p$ to Early-Onset NonInsulin-Dependent Diabetes Mellitus. Nature (1992) 356:162-4. doi: 10.1038/ 356162a0

18. Chakera AJ, Steele AM, Gloyn AL, Shepherd MH, Shields B, Ellard S, et al. Recognition and Management of Individuals With Hyperglycemia Because of a Heterozygous Glucokinase Mutation. Diabetes Care (2015) 38:1383-92. doi: $10.2337 / \mathrm{dc} 14-2769$

19. Chakera AJ, Spyer G, Vincent N, Ellard S, Hattersley AT, Dunne FP. The $0.1 \%$ of the Population With Glucokinase Monogenic Diabetes can be Recognized by Clinical Characteristics in Pregnancy: The Atlantic Diabetes in Pregnancy Cohort. Diabetes Care (2014) 37:1230-6. doi: 10.2337/dc13-2248

20. Osbak KK, Colclough K, Saint-Martin C, Beer NL, Bellanné-Chantelot C, Ellard S, et al. Update on Mutations in Glucokinase (GCK), Which Cause Maturity-Onset Diabetes of the Young, Permanent Neonatal Diabetes, and Hyperinsulinemic Hypoglycemia. Hum Mutat (2009) 30:1512-26. doi: 10.1002/humu.21110

21. Stride A, Vaxillaire M, Tuomi T, Barbetti F, Njølstad PR, Hansen T, et al. The Genetic Abnormality in the Beta Cell Determines the Response to an Oral Glucose Load. Diabetologia (2002) 45:427-35. doi: 10.1007/s00125-001-0770-9

22. Sturis J, Kurland IJ, Byrne MM, Mosekilde E, Froguel P, Pilkis SJ, et al. Compensation in Pancreatic Beta-Cell Function in Subjects With Glucokinase Mutations. Diabetes (1994) 43:718-23. doi: 10.2337/diab.43.5.718

23. Zhang H, Colclough K, Gloyn AL, Pollin TI. Monogenic Diabetes: A Gateway to Precision Medicine in Diabetes. J Clin Invest (2021) 131:e142244. doi: 10.1172/JCI142244

24. Matschinsky FM, Wilson DF. The Central Role of Glucokinase in Glucose Homeostasis: A Perspective 50 Years After Demonstrating the Presence of the Enzyme in Islets of Langerhans. Front Physiol (2019) 10:148. doi: 10.3389/ fphys.2019.00148

25. Byrne MM, Sturis J, Clément K, Vionnet N, Pueyo ME, Stoffel M, et al. Insulin Secretory Abnormalities in Subjects With Hyperglycemia Due to Glucokinase Mutations. J Clin Invest (1994) 93:1120-30. doi: 10.1172/JCI117064

26. Velho G, Petersen KF, Perseghin G, Hwang JH, Rothman DL, Pueyo ME, et al. Impaired Hepatic Glycogen Synthesis in Glucokinase-Deficient (MODY-2) Subjects. J Clin Invest (1996) 98:1755-61. doi: 10.1172/JCI118974

27. Guenat E, Seematter G, Philippe J, Temler E, Jequier E, Tappy L. Counterregulatory Responses to Hypoglycemia in Patients With Glucokinase Gene Mutations. Diabetes Metab (2000) 26:377-84.

28. Chakera AJ, Hurst PS, Spyer G, Ogunnowo-Bada EO, Marsh WJ, Riches CH, et al. Molecular Reductions in Glucokinase Activity Increase CounterRegulatory Responses to Hypoglycemia in Mice and Humans With Diabetes. Mol Metab (2018) 17:17-27. doi: 10.1016/j.molmet.2018.08.001

29. Clément K, Pueyo ME, Vaxillaire M, Rakotoambinina B, Thuillier F, Passa P, et al. Assessment of Insulin Sensitivity in Glucokinase-Deficient Subjects. Diabetologia (1996) 39:82-90. doi: 10.1007/BF00400417

30. Massa O, Meschi F, Cuesta-Munoz A, Caumo A, Cerutti F, Toni S, et al. High Prevalence of Glucokinase Mutations in Italian Children With MODY. Influence on Glucose Tolerance, First-Phase Insulin Response, Insulin Sensitivity and BMI. Diabetologia (2001) 44:898-905. doi: 10.1007/ s001250100530

31. Arslanian S, El Ghormli L, Haymond MH, Chan CL, Chernausek SD, Gandica RG, et al. Beta Cell Function and Insulin Sensitivity in Obese Youth With Maturity Onset Diabetes of Youth Mutations vs Type 2 Diabetes in TODAY: Longitudinal Observations and Glycemic Failure. Pediatr Diabetes (2020) 21:575-85. doi: 10.1111/pedi.12998

32. Martin D, Bellanné-Chantelot C, Deschamps I, Froguel P, Robert JJ, Velho G. Long-Term Follow-Up of Oral Glucose Tolerance Test-Derived Glucose Tolerance and Insulin Secretion and Insulin Sensitivity Indexes in Subjects With Glucokinase Mutations (MODY2). Diabetes Care (2008) 31:1321-3. doi: $10.2337 / \mathrm{dc} 07-2017$

33. Pearson ER, Velho G, Clark P, Stride A, Shepherd M, Frayling TM, et al. BetaCell Genes and Diabetes: Quantitative and Qualitative Differences in the Pathophysiology of Hepatic Nuclear Factor-1alpha and Glucokinase Mutations. Diabetes (2001) 50(Suppl 1):S101-7. doi: 10.2337/diabetes. 50.2007.s101
34. Ellard S, Bellanné-Chantelot C, Hattersley ATEuropean Molecular Genetics Quality Network (EMQN) MODY group. Best Practice Guidelines for the Molecular Genetic Diagnosis of Maturity-Onset Diabetes of the Young. Diabetologia (2008) 51:546-53. doi: 10.1007/s00125-008-0942-y

35. Steele AM, Wensley KJ, Ellard S, Murphy R, Shepherd M, Colclough K, et al. Use of HbAlc in the Identification of Patients With Hyperglycaemia Caused by a Glucokinase Mutation: Observational Case Control Studies. PloS One (2013) 8:e65326. doi: 10.1371/journal.pone.0065326

36. Steele AM, Shields BM, Wensley KJ, Colclough K, Ellard S, Hattersley AT. Prevalence of Vascular Complications Among Patients With Glucokinase Mutations and Prolonged, Mild Hyperglycemia. JAMA (2014) 311:279-86. doi: 10.1001/jama.2013.283980

37. Stride A, Shields B, Gill-Carey O, Chakera AJ, Colclough K, Ellard S, et al. Cross-Sectional and Longitudinal Studies Suggest Pharmacological Treatment Used in Patients With Glucokinase Mutations Does Not Alter Glycaemia. Diabetologia (2014) 57:54-6. doi: 10.1007/s00125-013-3075-x

38. Carmody D, Naylor RN, Bell CD, Berry S, Montgomery JT, Tadie EC, et al. GCK-MODY in the US National Monogenic Diabetes Registry: Frequently Misdiagnosed and Unnecessarily Treated. Acta Diabetol (2016) 53:703-8. doi: 10.1007/s00592-016-0859-8

39. Shepherd MH, Shields BM, Hudson M, Pearson ER, Hyde C, Ellard S, et al. A UK Nationwide Prospective Study of Treatment Change in MODY: Genetic Subtype and Clinical Characteristics Predict Optimal Glycaemic Control After Discontinuing Insulin and Metformin. Diabetologia (2018) 61:2520-7. doi: $10.1007 / \mathrm{s} 00125-018-4728-6$

40. Bacon S, Schmid J, McCarthy A, Edwards J, Fleming A, Kinsley B, et al. The Clinical Management of Hyperglycemia in Pregnancy Complicated by Maturity-Onset Diabetes of the Young. Am J Obstet Gynecol (2015) 213:236. doi: 10.1016/j.ajog.2015.04.037

41. López Tinoco C, Sánchez Lechuga B, Bacon S, Colclough K, Ng N, Wong E, et al. Evaluation of Pregnancy Outcomes in Women With GCK-MODY. Diabetes Med (2021) 38:e14488. doi: 10.1111/dme.14488

42. Dickens LT, Letourneau LR, Sanyoura M, Greeley SAW, Philipson LH, Naylor RN. Management and Pregnancy Outcomes of Women With GCK-MODY Enrolled in the US Monogenic Diabetes Registry. Acta Diabetol (2019) 56:405-11. doi: 10.1007/s00592-018-1267-z

43. Taylor RAM, Mackie A, Mogra R, Pinner J, Rajendran S, Ross GP. Caudal Regression Syndrome in a Fetus of a Glucokinase-Maturity-Onset Diabetes of the Young Pregnancy. Diabetes Med (2019) 36:252-5. doi: 10.1111/dme.13844

44. Rudland VL, Pinner J, Ross GP. Congenital Anomalies in Offspring of Maternal Glucokinase-Maturity-Onset Diabetes of the Young: A Case Report. Diabetes Care (2019) 42:e162-3. doi: 10.2337/dc19-0930

45. Langer O, Mazze R. The Relationship Between Large-for-Gestational-Age Infants and Glycemic Control in Women With Gestational Diabetes. Am J Obstet Gynecol (1988) 159:1478-83. doi: 10.1016/0002-9378(88)90578-9

46. Study Cooperative Research Group HAPO, Metzger BE, Lowe LP, Dyer AR, Trimble ER, Chaovarindr U, et al. Hyperglycemia and Adverse Pregnancy Outcomes. N Engl J Med (2008) 358:1991-2002. doi: 10.1056/NEJMoa0707943

47. Hattersley AT, Beards F, Ballantyne E, Appleton M, Harvey R, Ellard S. Mutations in the Glucokinase Gene of the Fetus Result in Reduced Birth Weight. Nat Genet (1998) 19:268-70. doi: 10.1038/953

48. Pedersen J. Diabetes and Pregnancy: Blood Sugar of Newborn Infants (Ph.D. Thesis) Vol. 230. . Copenhagen (Denmark: Danish Science Press (1952).

49. Velho G, Hattersley AT, Froguel P. Maternal Diabetes Alters Birthweight in Glucokinase-Deficient (MODY2) Kindred But has No Influence on Adult Weight, Height, Insulin Secretion or Insulin Sensitivity. Diabetologia (2000) 43:1060-3. doi: 10.1007/s001250051490

50. Spyer G, Macleod KM, Shepherd M, Ellard S, Hattersley AT. Pregnancy Outcome in Patients With Raised Blood Glucose Due to a Heterozygous Glucokinase Gene Mutation. Diabetes Med (2009) 26:14-8. doi: 10.1111/ j.1464-5491.2008.02622.x

51. de Las Heras J, Martínez R, Rica I, de Nanclares GP, Vela A, Castaño L, et al. Heterozygous Glucokinase Mutations and Birth Weight in Spanish Children. Diabetes Med (2010) 27:608-10. doi: 10.1111/j.1464-5491.2010.02953.x

52. Hosokawa Y, Higuchi S, Kawakita R, Hata I, Urakami T, Isojima T, et al. Pregnancy Outcome of Japanese Patients With Glucokinase-Maturity-Onset Diabetes of the Young. J Diabetes Investig (2019) 10:1586-9. doi: 10.1111/ jdi.13046 
53. Pettitt DJ, Aleck KA, Baird HR, Carraher MJ, Bennett PH, Knowler WC. Congenital Susceptibility to NIDDM. Role intrauterine environ Diabetes (1988) 37(5):622-8. doi: 10.2337/diab.37.5.622

54. Gautier JF, Wilson C, Weyer C, Mott D, Knowler WC, Cavaghan M, et al. Low Acute Insulin Secretory Responses in Adult Offspring of People With Early Onset Type 2 Diabetes. Diabetes (2001) 50:1828-33. doi: 10.2337/diabetes. 50.8.1828

55. Singh R, Pearson E, Avery PJ, McCarthy MI, Levy JC, Hitman GA, et al. Reduced Beta Cell Function in Offspring of Mothers With Young-Onset Type 2 Diabetes. Diabetologia (2006) 49:1876-80. doi: 10.1007/s00125-006-0285-5

56. Stride A, Shepherd M, Frayling TM, Bulman MP, Ellard S, Hattersley AT. Intrauterine Hyperglycemia Is Associated With an Earlier Diagnosis of Diabetes in HNF-1alpha Gene Mutation Carriers. Diabetes Care (2002) 25:2287-91. doi: 10.2337/diacare.25.12.2287

57. Sobngwi E, Boudou P, Mauvais-Jarvis F, Leblanc H, Velho G, Vexiau P, et al. Effect of a Diabetic Environment In Utero on Predisposition to Type 2 Diabetes. Lancet (2003) 361:1861-5. doi: 10.1016/S0140-6736(03)13505-2

58. Singh R, Person ER, Clark PM, Hattersley AT. The Long-Term Impact of Exposure to Hyperglycaemia In Utero Due to Maternal Glucokinase Gene Mutations. Diabetologia (2007) 50:620-4. doi: 10.1007/s00125-006-0541-8

59. Shields BM, Shepherd M, Hudson M, McDonald TJ, Colclough K, Peters J, et al. Population-Based Assessment of a Biomarker-Based Screening Pathway to Aid Diagnosis of Monogenic Diabetes in Young-Onset Patients. Diabetes Care (2017) 40:1017-25. doi: 10.2337/dc17-0224

60. American Diabetes Association. Classification and Diagnosis of Diabetes. Diabetes Care (2021) ) 44(Suppl 1):S15-33. doi: 10.2337/dc21-S002

61. Benhalima K, Minschart C, Van Crombrugge P, Calewaert P, Verhaeghe J, Vandamme S, et al. The 2019 Flemish Consensus on Screening for Overt Diabetes in Early Pregnancy and Screening for Gestational Diabetes Mellitus. Acta Clin Belg (2020) 75:340-7. doi: 10.1080/17843286.2019.1637389

62. Benhalima K, Van Crombrugge P, Moyson C, Verhaeghe J, Vandeginste S, Verlaenen $\mathrm{H}$, et al. Women With Mild Fasting Hyperglycemia in Early Pregnancy Have More Neonatal Intensive Care Admissions. J Clin Endocrinol Metab (2021) 106:e836-54. doi: 10.1210/clinem/dgaa831

63. Colom C, Corcoy R. Maturity Onset Diabetes of the Young and Pregnancy. Best Pract Res Clin Endocrinol Metab (2010) 24:605-15. doi: 10.1016/ j.beem.2010.05.008

64. Bitterman O, Giuliani C, Festa C, Napoli A. Glucokinase Deficit Prevalence in Women With Diabetes in Pregnancy: A Matter of Screening Selection. Front Endocrinol (Lausanne) (2020) 11:268. doi: 10.3389/fendo.2020.00268

65. Rudland VL, Hinchcliffe M, Pinner J, Cole S, Mercorella B, Molyneaux L, et al. Identifying Glucokinase Monogenic Diabetes in a Multiethnic Gestational Diabetes Mellitus Cohort: New Pregnancy Screening Criteria and Utility of HbAlc. Diabetes Care (2016) 39:50-2. doi: 10.2337/dc15-1001

66. Gjesing AP, Rui G, Lauenborg J, Have CT, Hollensted M, Andersson E, et al. High Prevalence of Diabetes-Predisposing Variants in MODY Genes Among Danish Women With Gestational Diabetes Mellitus. J Endocr Soc (2017) 1:681-90. doi: 10.1210/js.2017-00040

67. Rudland VL. Diagnosis and Management of Glucokinase Monogenic Diabetes in Pregnancy: Current Perspectives. Diabetes Metab Syndr Obes (2019) 12:1081-9. doi: 10.2147/DMSO.S186610

68. Spyer G, Hattersley AT, Sykes JE, Sturley RH, MacLeod KM. Influence of Maternal and Fetal Glucokinase Mutations in Gestational Diabetes. Am J Obstet Gynecol (2001) 185:240-1. doi: 10.1067/mob.2001.113127

69. Tagliaferri F, Grosso C, Balbo M, Bracciolini G, Bertelli E, Secco A, et al. A Novel Mutation in GCK Gene: Beware of SGA Child With Diabetic Mother. Diabetes Res Clin Pract (2021) 181:109081. doi: 10.1016/j.diabres.2021. 109081

70. Chakera AJ, Carleton VL, Ellard S, Wong J, Yue DK, Pinner J, et al. Antenatal Diagnosis of Fetal Genotype Determines If Maternal Hyperglycemia Due to a Glucokinase Mutation Requires Treatment. Diabetes Care (2012) 35:1832-4. doi: $10.2337 / \mathrm{dc} 12-0151$

71. Misra S, Dornhorst A. Gestational Diabetes Mellitus: Primum non Nocere. Diabetes Care (2012) 35:1811-3. doi: 10.2337/dc12-0689

72. Langer O, Levy J, Brustman L, Anyaegbunam A, Merkatz R, Divon M. Glycemic Control in Gestational Diabetes Mellitus-How Tight Is Tight Enough: Small for Gestational Age Versus Large for Gestational Age? Am J Obstet Gynecol (1989) 161:646-53. doi: 10.1016/0002-9378(89)90371-2
73. Buchanan TA, Kjos SL, Montoro MN, Wu PYK, Madrilejo NG, Gonzalez M, et al. Use of Fetal Ultrasound to Select Metabolic Therapy for Pregnancies Complicated by Mild Gestational Diabetes. Diabetes Care (1994) 17:275-83. doi: $10.2337 /$ diacare.17.4.275

74. Kjos SL, Schaefer-Graf U, Sardesi S, Peters RK, Buley A, Xiang AH, et al. A Randomized Controlled Trial Using Glycemic Plus Fetal Ultrasound Parameters Versus Glycemic Parameters to Determine Insulin Therapy in Gestational Diabetes With Fasting Hyperglycemia. Diabetes Care (2001) 24:1904-10. doi: 10.2337/diacare.24.11.1904

75. Schaefer-Graf UM, Kjos SL, Fauzan OH, Bühling KJ, Siebert G, Bührer C, et al. A Randomized Trial Evaluating a Predominately Fetal Growth-Based Strategy to Guide Management of Gestational Diabetes in Caucasian Women. Diabetes Care (2004) 27:297-302. doi: 10.2337/diacare.27.2.297

76. Bonomo M, Cetin I, Pisoni MP, Faden D, Mion E, Taricco E, et al. Flexible Treatment of Gestational Diabetes Modulated on Ultrasound Evaluation of Intrauterine Growth: A Controlled Randomized Clinical Trial. Diabetes Metab (2004) 30:237-43. doi: 10.1016/s1262-3636(07)70114-3

77. Kjos SL, Schaefer-Graf UM. Modified Therapy for Gestational Diabetes Using High-Risk and Low-Risk Fetal Abdominal Circumference Growth to Select Strict Versus Relaxed Maternal Glycemic Targets. Diabetes Care (2007) 30 (Suppl 2):S200-5. doi: 10.2337/dc07-s216

78. Quevedo SF, Bovbjerg ML, Kington RL. Translation of Fetal Abdominal Circumference-Guided Therapy of Gestational Diabetes Complicated by Maternal Obesity to a Clinical Outpatient Setting. J Matern Fetal Neonatal Med (2017) 30:1450-5. doi: 10.1080/14767058.2016.1219987

79. Rao U, de Vries B, Ross GP, Gordon A. Fetal Biometry for Guiding the Medical Management of Women With Gestational Diabetes Mellitus for Improving Maternal and Perinatal Health. Cochrane Database Syst Rev (2019) 9:CD012544. doi: 10.1002/14651858.CD012544.pub2

80. Mirabelli M, Chiefari E, Tocci V, Greco E, Foti D, Brunetti A. Gestational Diabetes: Implications for Fetal Growth, Intervention Timing, and Treatment Options. Curr Opin Pharmacol (2021) 60:1-10. doi: 10.1016/ j.coph.2021.06.003

81. Scotchman E, Chandler NJ, Mellis R, Chitty LS. Noninvasive Prenatal Diagnosis of Single-Gene Diseases: The Next Frontier. Clin Chem (2020) 66:53-60. doi: 10.1373/clinchem.2019.304238

82. Caswell RC, Snowsill T, Houghton JAL, Chakera AJ, Shepherd MH, Laver TW, et al. Noninvasive Fetal Genotyping by Droplet Digital PCR to Identify Maternally Inherited Monogenic Diabetes Variants. Clin Chem (2020) 66:958-65. doi: 10.1093/clinchem/hvaa104

83. Kwak SH, Powe CE, Jang SS, Callahan MJ, Bernstein SN, Lee SM, et al. Sequencing Cell-Free Fetal DNA in Pregnant Women With GCK-MODY J Clin Endocrinol Metab (2021) 106:2678-89. doi: 10.1210/clinem/dgab265

84. Nouspikel T, Blouin JL, Puder JJ, Köhler Ballan B, Schwitzgebel VM. Precision Medicine in Diabetes: A Non-Invasive Prenatal Diagnostic Test for the Determination of Fetal Glucokinase Mutations. J Diabetes Investig (2021). doi: $10.1111 /$ jdi.13656

85. Mello G, Parretti E, Mecacci F, La Torre P, Cioni R, Cianciulli D, et al. What Degree of Maternal Metabolic Control in Women With Type 1 Diabetes Is Associated With Normal Body Size and Proportions in Full-Term Infants? Diabetes Care (2000) 23(10):1494-8. doi: 10.2337/diacare.23.10.1494

86. Murphy HR. Continuous Glucose Monitoring Targets in Type 1 Diabetes Pregnancy: Every 5\% Time in Range Matters. Diabetologia (2019) 62:1123-28. doi: 10.1007/s00125-019-4904-3

87. Ringholm L, Pedersen-Bjergaard U, Thorsteinsson B, Damm P, Mathiesen ER. Hypoglycaemia During Pregnancy in Women With Type 1 Diabetes. Diabetes Med (2012) 29:558-66. doi: 10.1111/j.1464-5491.2012.03604.x

88. Yamamoto JM, Murphy HR. Benefits of Real-Time Continuous Glucose Monitoring in Pregnancy. Diabetes Technol Ther (2021) 23(S1):S8-14. doi: $10.1089 /$ dia.2020.0667

89. Stewart ZA, Wilinska ME, Hartnell S, O'Neil LK, Rayman G, Scott EM, et al. Day-And-Night Closed-Loop Insulin Delivery in a Broad Population of Pregnant Women With Type 1 Diabetes: A Randomized Controlled Crossover Trial. Diabetes Care (2018) 41:1391-9. doi: 10.2337/dc17-2534

90. Finneran MM, Landon MB. Oral Agents for the Treatment of Gestational Diabetes. Curr Diabetes Rep (2018) 18:119. doi: 10.1007/s11892-018-1093-2

91. Tarry-Adkins JL, Aiken CE, Ozanne SE. Neonatal, Infant, and Childhood Growth Following Metformin Versus Insulin Treatment for Gestational 
Diabetes: A Systematic Review and Meta-Analysis. PloS Med (2019) 16: e1002848. doi: 10.1371/journal.pmed.1002848

Conflict of Interest: The authors declare that the research was conducted in the absence of any commercial or financial relationships that could be construed as a potential conflict of interest.

Publisher's Note: All claims expressed in this article are solely those of the authors and do not necessarily represent those of their affiliated organizations, or those of the publisher, the editors and the reviewers. Any product that may be evaluated in this article, or claim that may be made by its manufacturer, is not guaranteed or endorsed by the publisher.

Copyright (c) 2022 Timsit, Ciangura, Dubois-Laforgue, Saint-Martin and BellanneChantelot. This is an open-access article distributed under the terms of the Creative Commons Attribution License (CC BY). The use, distribution or reproduction in other forums is permitted, provided the original author(s) and the copyright owner $(s)$ are credited and that the original publication in this journal is cited, in accordance with accepted academic practice. No use, distribution or reproduction is permitted which does not comply with these terms. 